\title{
Hypoxic signature of microRNAs in glioblastoma: insights from small RNA deep sequencing
}

\author{
Rahul Agrawall, Priyatama Pandey ${ }^{2}$, Prerana Jha ${ }^{3}$, Vivek Dwivedi ${ }^{1}$, Chitra Sarkar $^{3^{*}}$ and Ritu Kulshreshtha ${ }^{{ }^{*}}$
}

\begin{abstract}
Background: Hypoxia is a critical aspect of the glioma microenvironment and has been associated with poor prognosis and resistance to various therapies. However, the mechanisms responsible for hypoxic survival of glioma cells remain unclear. Recent studies strongly suggest that microRNAs act as critical mediators of the hypoxic response. We thus hypothesized their prominent role in hypoxia resistance in glioblastoma (GBM) and aimed to identify those.

Results: With this study, we present the first detailed analysis of small RNA transcriptome of cell line U87MG, a grade IV glioma cell line, and its alteration under hypoxic condition. Based on deep sequencing and microarray data, we identify a set of hypoxia regulated microRNAs, with the miR-210-3p and its isomiRs showing highest induction in GBM cell lines U87MG and U251MG. We show miR-210-3p, miR-1275, miR-376c-3p, miR-23b-3p, miR-193a-3p and miR-145-5p to be up-regulated, while miR-92b-3p, miR-20a-5p, miR-10b-5p, miR-181a-2-3p and miR-185-5p are down-regulated by hypoxia. Interestingly, certain hypoxia-induced miRNAs are also known to be over-expressed in GBM tumors, suggesting that hypoxia may be one of the factors involved in establishing the miRNA signature of GBM. Transcription factor binding sites for Hypoxia inducible factor 1 A (HIF1A) were identified in the promoter region (5 kb upstream) of 30 hypoxia-induced miRNAs. HIF-1A over-expression and silencing studies show regulation of specific miRNAs, including miR-210-3p, to be HIF1A dependent. On the other hand, miR-210-3p leads to an increase in transcriptional activity of HIF and its target genes vascular endothelial growth factor (VEGF) and carbonic anhydrase 9 (CA9). MiR-210-3p levels were found to be high in GBM patient samples and showed good correlation with the known hypoxia markers CA9 and VEGF. We show that miR-210-3p promotes hypoxic survival and chemoresistance in GBM cells and targets a negative regulator of hypoxic response, HIF3A. Additionally, a total of 139 novel miRNAs were discovered by the analysis of deep sequencing data and three of these were found to be differentially expressed under hypoxia.

Conclusions: Overall, our study reveals a novel miRNA signature of hypoxia in GBM and suggests miR-210-3p to be an oncogenic player and a novel potential intrinsic marker of hypoxia in glioblastoma.
\end{abstract}

Keywords: Glioblastoma, MicroRNA, Deep sequencing, U87MG, U251MG, A172, miR-210

\section{Background}

Hypoxia, or low oxygenation, has emerged as an important factor in tumor biology and response to cancer treatment [1]. It has been shown to be a negative prognostic factor for several cancers, including those of the cervix, head and neck, prostate, pancreas, and brain [2]. GBM is the most

\footnotetext{
*Correspondence: sarkar.chitra@gmail.com; drritukulshreshtha@gmail.com ${ }^{3}$ Department of Pathology, All India Institute of Medical Sciences, 110029 New Delhi, India

'Department of Biochemical Engineering and Biotechnology, Indian Institute of Technology, 110016 New Delhi, India

Full list of author information is available at the end of the article
}

common primary brain tumor, representing about $17 \%$ of all primary brain tumors and about $60-75 \%$ of all astrocytomas [3,4]. The severity of tumor hypoxia is known to strongly correlate to tumor progression, metastasis, invasion, therapeutic resistance [5,6]. High levels of hypoxic markers like VEGF, CA9 and OPN are correlated with poor prognosis for GBM patients $[7,8]$. Recent report shows that the hypoxic microenvironment maintains glioblastoma stem cells and promotes reprogramming towards a cancer stem cell phenotype [9]. This suggests to target hypoxia, or hypoxia-regulated genes for therapeutic purposes. However, the results have been 
unsatisfactory so far, emphasizing the need to identify novel players in hypoxia signalling as potential targets for cancer therapy.

MicroRNAs (a class of small non-coding RNAs) have emerged as key players in cellular transformation and tumorigenesis and show great potential for cancer diagnostics and therapeutics [10,11]. Recent studies strongly indicate that miRNAs are involved in the pathogenesis of GBM [12]. The first report demonstrating altered expression of microRNAs in GBM was published in 2005 [13]. MiR-21 was the first miRNA found strongly upregulated in six cell lines of GBM and is now established as an important oncogene that targets multiple components of p53 and transforming growth factor-beta (TGF-beta) pathways in GBM cells [14]. Functional analysis of other miRNAs aberrantly expressed in GBM, like miR-221/222, -34a, $-146 \mathrm{~b}$ and $-10 \mathrm{~b}$, showed an influence on cell cycle, glioma cell migration and invasion and stem cell properties [15-17]. Recently, Moore et al. showed that during progression from low grade to high grade glioma, the amount of mature miRNAs increases in comparison to precursor hairpins [18].

Importantly, miRNAs have also been recently reported to act as critical mediators of hypoxia signalling [19]. The pioneering work by Ivan's group shows that a specific set of hypoxia-regulated miRNAs (HRMs) modulates cell cycle, apoptosis and DNA repair pathways in response to hypoxia in breast cancer [20-22]. Since then, several studies have found that HRMs fine- tune their hypoxic response through cellular processes such as angiogenesis, cell cycle regulation, metabolism, apoptosis, metastasis, proliferation and resistance to anticancer therapy [23].

Considering the wide impact of miRNAs in hypoxic tumor biology, it seems important to identify and functionally characterize HRMs in GBM. This can give insight into the molecular mechanism of hypoxia-resistance in GBM and might have implication for GBM diagnosis and therapy. In this study, we used deep-sequencing profiling of small RNAs (sRNAs), along with microarray hybridization to study the expression pattern of miRNAs in response to hypoxia in a GBM cell line (U87MG). The advantage of deep sequencing over other detection methods, like northern blot analysis, RNAase protection assays, microarray chip techniques or real-time PCR, lies in the ability to detect low abundant and novel transcripts. The signature we obtained contains known as well as novel miRNAs. Subsets of these were found to carry HIF1A response elements (HREs) in their promoters and were shown to be HIF-1A regulated. Interestingly, a well-known HRM, miR-210-3p, was found to be highly induced in hypoxic glioma cell lines (U87MG and U251MG) as well as in hypoxic GBM tumor samples, suggesting its use as a hypoxia marker or therapeutic target in GBM. Based on our results, miR-210-3p promotes survival of GBM cells in the tumor microenvironment, promotes aggressiveness by imparting temozolomide resistance and targets HIF3A, which is known to function as a negative regulator of hypoxia-inducible gene expression [24].

\section{Methods \\ Cell culture}

Cell line U87MG was obtained from the National Centre for Cell Sciences, Pune. U251MG and A172 were kind gifts from Dr. Kunzang Chosdol (AIIMS, Delhi, India) and Dr. Ellora Sen (NBRC, Manesar, India), respectively. All cell lines were maintained in DMEM medium. The medium was supplemented with $10 \%$ Fetal Bovine Serum, 100 U/ml penicillin and $100 \mu \mathrm{g} / \mathrm{ml}$ streptomycin. It was incubated at $37^{\circ} \mathrm{C}$ and $5 \% \mathrm{CO}_{2}$. To create hypoxic conditions, cells were grown in a hypoxia workstation (In vivo 200, Ruskinn Technology Ltd., UK) at $0.2 \% \mathrm{O}_{2}, 5 \% \mathrm{CO}_{2}$ and $37^{\circ} \mathrm{C}$.

\section{Glioblastoma patient samples}

Thirty samples of human glioblastoma (GBM: WHO Grade IV) were obtained from the Neuropathology Laboratory of the Department of Pathology, All India Institute of Medical Sciences (AIIMS), New Delhi. The study was approved by the ethical committee of the institute. Cases were selected on the basis of availability of adequate tumor tissue. The haematoxylin- and eosin- (H\&E) stained slides of these cases were reviewed and a concordant agreement was established on the diagnosis between three trained pathologists, based on the WHO 2007 tumor classification [25]. Clinical data, viz. age, sex and history were noted. The age range of the patients was from 19 to 80 years, and the mean age was about 51 . The male to female ratio was around 1.5. All cases were de novo primary GBMs. Five control brain tissues were also obtained from cases of epilepsy surgery. We used the epileptic tissue as nonneoplastic reference, as this serves as best control. We avoided the use of tissue adjacent to the tumor as control, since there is the possibility of tumor cell infiltration.

\section{Transient and stable transfections}

U87MG cells were seeded in 6 well plates $\left(3 \times 10^{5}\right.$ cells/well) $24 \mathrm{~h}$ before transfection. Cells were transfected with plasmid $(2.5 \mu \mathrm{g})$, using transfection reagent Lipofectamine 2000 (Invitrogen). In case of the miR-210 inhibitor and the respective control (Sigma), $30 \mathrm{nM}$ of each were transfected. The plasmids - pCDNA3.1, pCDNA3.1-HIF1A, pLK0.1-shGFP and pLK0.1-shHIF1A were a kind gift from Dr. Mircea Ivan (Indiana University, IN).

\section{Construction of stable polyclonal cell lines}

The miR-210 overexpressing vector (pBABE-miR-210) or the empty parent vector pBABE-puro were prepared as described in Crosby et al., [26]. The plasmids were 
then transfected into U87MG cells, and stable polyclonal cell lines were selected with $2 \mu \mathrm{g} / \mathrm{ml}$ puromycin for up to one month.

\section{Hypoxia, serum starvation and drug treatment}

The stable polyclonal cell lines were seeded in 24-well plate $\left(5 \times 10^{4}\right.$ cells/well) in triplicate. For hypoxic stress, the cells were placed $24 \mathrm{~h}$ post-seeding in a hypoxia chamber maintaining $0.2 \%$ oxygen and $5 \% \mathrm{CO} 2$. For serum starvation, the supplemented medium was replaced with medium lacking serum. For drug treatment, temozolomide was added to a concentration of $5 \mu \mathrm{M}$. Cell survival was quantified at different time points using 3-(4,5-dimethylthiazole-2-yl)-2,5diphenyl tetrazolium bromide (MTT) at $595 \mathrm{~nm}$.

\section{RNA isolation}

Cells were suspended in TRIzol (Invitrogen), and total RNA was isolated according to the manufacturer's protocol using the GeneJET ${ }^{\mathrm{TM}}$ RNA purification kit. To isolate RNA from tumor tissues, tissues were pre-treated with xylene and protease, followed by RNA isolation using an RNA isolation kit (Ambion) according to the manufacturer's protocol. The concentration and purity of the extracted RNA was measured with a NANODROP 2000c spectrophotometer (Thermo Scientific). RNA was stored at $-80^{\circ} \mathrm{C}$.

\section{Small RNA preparation}

Total RNA was isolated using TRIzol, and isolated RNA was run on a denaturing polyacrylamide gel. A section of the gel was cut out that corresponded to RNA of 16-30 nucleotides, as judged using a standard oligonucleotide marker. After size fractionation, of the sRNA, a ligation step was carried out. A single-stranded DNA 5' adaptor, followed by a 3 ' adaptor, was ligated to the small RNAs. The ligation products (70-90 nucleotides) were purified using urea-PAGE. The adaptors act as primer binding sites for reverse transcription and PCR amplification. Adaptor-ligated sRNAs were reverse-transcribed and amplified by PCR. The resulting cDNA tag libraries were sequenced with an Illumina genome analyzer.

\section{Analysis of deep sequencing data}

The total sequences from the normoxic and hypoxic samples numbered 12,577,383 and 7,110,799, respectively. After 3' adaptor removal and length range filtering (16-35), $7,297,894$ and 5,256,222 sequences, respectively, remained. The following databases were used in the analysis of our deep sequencing data:

A. Mature miRNAs: miRBase, release 20.

B. ncRNAs: Ensembl "Homo_sapiens.CRCh37.69.ncrna. fa.red" (includes precursor miRNAs and other ncRNAs).

C. piRNA: piRNA Bank.
D. RNA database: NCBI FTP site (includes rRNAs and mRNAs).

E. Exons and intergenic/intronic sequences: obtained through in-house built perl script using the reference contig files from the NCBI FTP site. A detailed analysis of the deep sequencing data is given in Additional file 1.

\section{Expression pattern of known MiRNAs}

To obtain the expression pattern of known miRNA, sequences from both samples were matched against known mature miRNA databases using an in-house built shell script. No mismatch was allowed, and sequences showing $100 \%$ similarity to a database entry were considered candidates for known mature miRNAs (Additional file 2).

\section{Data normalization}

Normalization is required to make data comparable across experiments and to reduce the impact of non-biological variability. We performed "transcript parts per million" (TPM) and "reads per kilobase per million" (RPKM) normalization for our samples. To calculate TPM, the number of reads or frequency of the sequence are divided by total clone count of the sample and multiplied by $10^{6}$ while to calculate RPKM, TPM values are divided by the nucleotide length of the mature miRNA. Total clone count is the sum of the frequencies of all sequences present in the sample.

\section{Differentially expressed MicroRNAs}

Known miRNAs expressed in normoxic sample were compared to those from hypoxic sample. A fold change of 1.5 was set as the minimum threshold to count as differential expression. A list of differentially expressed miRNAs is given in Additional file 3.

\section{Identification of novel MiRNAs}

Sequences from both samples were matched against the above mentioned already existing and compiled databases, from mature miRNAs to intronic sequences. An elimination pipeline was used in the prediction process for novel miRNAs [27]. An elimination pipeline perl script was used for the alignments, and a mismatch of up to 2 nucleotides was allowed. Sequences that exactly matched intergenic/intronic regions were extracted along with 70 nucleotides flanking on either side. These sequences served as potential precursor miRNAs. The sequences were then analysed with the miRNA prediction algorithm tool CID-miRNA [28]. Folded precursors predicted by this program were then checked for the presence of sRNA. After this, those hairpins were considered as potential precursor, in which the mature sequence arises from the stem portion and not from the loop part. This 
prediction was further checked with MiPred [29]. The list of novel miRNAs is given in Additional file 4.

\section{IsomiRs of novel MiRNAs}

A list of all the predicted novel miRNA precursors was created. Sequences that differed from the representative mature miRNA by a few nucleotides at the $5^{\prime}$ - or $3^{\prime}$-end were listed as isomiRs. A representative mature miRNA was selected on the basis of presence of highest number of sequence reads. IsomiRs of miR-210 were identified in an equivalent way.

\section{Microarray expression profiling and analysis}

U87MG cells were kept under normoxia $\left(21 \% \mathrm{O}_{2}\right)$ or hypoxia $\left(0.2 \% \mathrm{O}_{2}\right)$ for $48 \mathrm{~h}$. Two technical replicates of total RNA were harvested and sent for microarray expression profiling (Genotypic Technology, Bangalore). The miRNA expression data were generated using Agilent Human miRNA $8 \times 15 \mathrm{k}$ arrays. The normalization was done using the software GeneSpring GX 11.5. Fold differences are provided in terms of log base 2 . A \pm 0.6 fold change (log base 2) cut-off was used for identifying differentially expressed miRNAs (Additional file 5).

\section{MiRNA and mRNA quantitation}

Candidate miRNAs were reverse-transcribed into cDNA using specific stem-loop RT primers (Additional file 6). Quantitation was done with a CFX96 ${ }^{\text {TM }}$ real time PCR system (Bio-RAD) using a cDNA-specific forward primer and a universal reverse primer, as listed in Additional file 6. RNU6B was used for normalization for all samples. A list of primers along with their sequences is given in Additional file 6.

To determine the transcript levels of HIF1A, HIF3A, VEGF and CA9, total RNA was reverse-transcribed into cDNA with the RevertAid first strand cDNA synthesis kit (Fermentas), using an oligo-dT primer. The cDNA was further amplified with gene specific primers using the Fermentas SYBR Green PCR master mix. GAPDH was used for normalization.

\section{Target prediction of MiR-210-3p and differentially regulated novel MiRs}

Potential targets of miR-210-3p were predicted using established target prediction programs. Targets were only further considered when predicted by at least three out of 11 target prediction programs (PITA, PicTar, miRanda, mirTarget2, TargetScan, NBmirTar, RNAhybrid, MicroInspector, MiTarget, RNA22 and DIANA MicroT), using the online software miRECORDS [30]. Potential targets of differentially regulated novel miRs were predicted by the TargetScan Human 5.2 custom program. A list of targets, along with their description, is given in Additional file 7.

\section{Prediction of HREs in the promoter of MiRNAs}

The miRNAs found to be up-regulated by hypoxia (based on deep sequencing or microarray profiling) were searched for the presence of HREs within the promoter region (within $5 \mathrm{~kb}$ upstream of the $5^{\prime}$ ends of pre miRNAs). The upstream region of these miRNAs was extracted from the Ensembl genome browser. HREs were predicted with program PROMO [31,32]. PROMO uses version 8.3 of the TRANSFAC database. A list of predicted HREs is given in Additional file 8.

\section{Construction of 3'-UTR-luciferase or promoter-luciferase constructs}

To determine whether miR-210-3p down-regulates target transcripts through direct binding to the $3^{\prime}$ untranslated region (UTR), the fragment of $3^{\prime}$ UTR of the target gene [hypoxia inducible factor 3A (HIF3A)] containing the miR-210-3p binding site was PCR-amplified and cloned into a luciferase reporter vector (pMIR-Report) downstream of a firefly luciferase gene. To further test whether the predicted target HIF3A is the direct target of miR-210-3p, the miR-210-3p binding site in the $3^{\prime}$ UTR of the HIF3A gene was mutated by site-directed mutagenesis, and luciferase activity was determined. All clones were confirmed by PCR, restriction digests and sequence analysis.

\section{Dual luciferase assay}

For luciferase assays, U87MG cells $\left(5 \times 10^{4}\right.$ cells/well $)$ were co-transfected with the $3^{\prime}$ UTR luciferase constructs along with vectors $\mathrm{pBABE}$ or pBABE-miR-210, using Lipofectamine 2000. pRL-TK was co-transfected in all wells for normalization of transfection efficiency. The activities of firefly (Photinus pyralis) and renilla (Renilla reniformis) luciferases were quantified $48 \mathrm{~h}$ post-transfection, using a dual luciferase reporter assay kit (Promega).

\section{Results}

\section{MicroRNA signature of hypoxia in GBM}

Though there are several reports on aberrant expression of miRNAs in hypoxic tumors, as determined by Next Generation Sequencing or microarrays, but none in GBM cells so far. Here, we present for the first time the small RNA transcriptome of U87MG, a model GBM cell line for the study glioma, and its aberrant miRNA expression profile under hypoxic conditions.

The U87MG cell line was exposed to normoxia $\left(21 \% \mathrm{O}_{2}\right)$ or hypoxia $\left(0.2 \% \mathrm{O}_{2}\right)$ for $48 \mathrm{~h}$. RNA was then harvested, processed (see above) and analysed by deep sequencing using the Illumina platform. A detailed analysis of the sRNA deep sequencing data with respect to read lengths, annotations, expression patterns and a list of highly expressed miRNAs and piRNAs are given in Additional files 1 and 2. The expression patterns of 
miRNA clusters were also investigated and, in agreement with the recent literature, miRNA genes present within the same cluster showed huge variability in their expression levels in GBM cells (Additional file 1).

The deep sequencing data were normalized according to TPM or RPKM, as described in the "Methods". A comparison of the normalized normoxic and hypoxic profiles of U87MG cells identified many differentially expressed miRNAs ( $>1.5$ fold regulated). A total of 141 miRNAs were found to be differentially regulated (102 up-regulated and 39 down-regulated) in response to hypoxia (Figure 1a and Additional file 3). The highly up-regulated miRNAs include miR-210-3p/5p, miR-196a5p, miR-629-3p, miR-23b-3p, miR-455-3p/5p, miR-3353p/5p, miR-129-5p/3p, miR-342-3p, miR-132-5p, miR382-3p, miR-193a-3p, miR-221-5p, miR-708-5p and miR183-5p (Figure 1a and Additional file 3). These miRNAs showed a more than 3-fold higher expression in hypoxic cells and are among the top twenty up-regulated miRNAs. Notably, miR-210, a miRNA shown to be hypoxia up-regulated in several cell lines of various tissues, showed highest induction of both miR-210-3p (25-fold) and miR-210-5p (12-fold) in response to hypoxia.

Among the down-regulated miRNAs, miR-29b-1-5p, miR-7974, miR-3607-3p, miR-589-3p, miR-92b-3p, miR485-5p, miR-4662a-5p, miR-16-2-3p, miR-20a-5p and miR-194-5p were found to be down-regulated by more than 2-fold in hypoxic cells (Figure 1a and Additional file 3).

We next checked which members of any miRNA cluster were co-regulated. Interestingly, we found that 29 miRNAs were upregulated as part of 11 miRNA clusters while members of the miR-374b cluster and miR-17/92 cluster were down-regulated (Figure 1b).

We compared the published GBM tumor and normal brain miRNA signatures with the GBM hypoxia miRNA signature and interestingly found that several of the hypoxia-induced miRNAs were also overexpressed in GBM, suggesting that the GBM-associated miRNA profile may have a hypoxia signature $[33,34]$ (Figure 1c).

We also conducted miRNA microarray profiling of U87MG cells grown in normoxia $\left(21 \% \mathrm{O}_{2}\right)$ or hypoxia $\left(0.2 \% \mathrm{O}_{2}\right)$ for $48 \mathrm{~h}$. A total of 10 microRNAs were found to be up regulated and 23 microRNAs were found to be down regulated in hypoxia [ $>0.6$-fold (log base 2), $\mathrm{p}<0.05$ ] (Additional file 5). A comparison of both microarray and deep sequencing data found miR-210-3p and miR-1275 to be up-regulated and miR-10b-5p, miR-181a-2-3p and miR-185-5p to be down-regulated, according to both data sets.

Generally, hypoxia-regulated genes or miRNAs bear HREs in their promoters, to which a transcription factor called HIF1 binds, which induces their expression
[19]. We therefore looked for the presence of HREs within the promoter regions of those miRNAs upregulated by hypoxia. A total of $5 \mathrm{~kb}$ upstream of these miRNAs was extracted, and HREs were predicted using the prediction program PROMO (details in the Methods). A total of 30 upregulated miRNA genes were found to contain one or more HREs (Figure 2 and Additional file 8).

We next validated the expression of the differentially regulated candidate miRNAs identified by deep sequencing or microarray profiling or both, using quantitative stem loop RT-PCR, which is used for detection of mature miRNAs (Figure 3a, b). Among the upregulated miRNAs, an additional criterion of presence of HREs in their promoter was considered for their validation. Notably, miR-210-3p was found to be most induced on the basis of qRT-PCR data too. To check for the universality of differential expression of miRNAs in normoxic $\mathrm{v} / \mathrm{s}$ hypoxic cells, the results were further verified for cell line U251MG. Out of 11 miRNAs tested, eight showed a similar expression pattern as in U87MG cells, with miR210-3p showing the highest induction (Additional file 9). However, expression of miR-376c-3p, miR-193a-3p and miR-10b-5p did not change significantly in response to hypoxia in U251MG cells, as opposed to U87MG. These differences could be due to several factors, including genotypic differences in the two cell lines, which are derived from two different GBM patients.

Often miRNAs exist in alternative forms, called "isomiRs" that differ from each other in terminal nucleotides. We analysed if the isomiR profile of miR-210 changes in normoxic versus hypoxic samples. A total of 320 isomiR species were detected, of which the normoxic samples expressed only 73, while the hypoxic samples expressed 312 isomiRs, of which 175 were singletons (Additional file 10). While the reference miR-210 sequence from miRBase was most abundant (Nor-396 and Hyp-7252 reads), several other miR-210 isomiRs also showed high expression levels, ranging from 113 to 699 among the highly expressed hypoxia sequences.

\section{Hypoxia-inducible factors (HIFs) and their role in miRNA induction}

HIFs are transcription factors that respond to hypoxia in the cellular environment [35]. Promoter regions of HRM genes contain HREs that are bound by HIF1 in response to hypoxia [19]. Many HRMs, such as miR-210 [19], -155 [36], -373 [37] have been shown before to bear HREs in their promoter regions and are dynamically regulated by HIF1 in response to hypoxia.

To evaluate HIF1-mediated induction of hypoxia-regulated miRNAs, U87MG cells were transfected with either a control (pCDNA3.1) or HIF1A-overexpressing plasmid (pCDNA3.1-HIF1A). Since HIF1A is degraded under 


\section{b Up regulated Clusters}

\begin{tabular}{|lrr|} 
& \multicolumn{2}{c}{$\begin{array}{c}\text { Normoxia } \\
\text { TPM }\end{array}$} \\
miR-382-3p & \multicolumn{2}{c}{ TPM } \\
\hline miR-154-5p & 3.3 & 10.5 \\
\hline miR-376c-3p & 8.6 & 20.4 \\
\hline miR-323a-3p & 26.2 & 63.4 \\
\hline miR-655-3p & 6.2 & 12.9 \\
\hline miR-134 & 5.9 & 15.2 \\
\hline & 25.3 & 40.1 \\
\hline
\end{tabular}

\begin{tabular}{lrr}
\hline miR-132-5p & 2.1 & 7.2 \\
\hline
\end{tabular}

\begin{tabular}{|rrr|}
\hline miR-132-3p & 27.3 & 56.1 \\
\hline miR-212-3p & 2.6 & 4.9 \\
\hline
\end{tabular}

$\begin{array}{lll}\text { miR-212-3p } & 2.6 & 4.9\end{array}$

\begin{tabular}{lll}
\hline miR-221-3p & 3093.0 & 4656.8 \\
\hline
\end{tabular}

\begin{tabular}{|lrr|}
\hline miR-221-3p & 3093.0 & 4656.8 \\
\hline miR-221-5p & 1.4 & 4.8 \\
\hline miR-222-3p & 99.5 & 162.3 \\
\hline
\end{tabular}

\begin{tabular}{lll} 
miR-222-3p & 99.5 & 162.3 \\
\hline
\end{tabular}

\begin{tabular}{|lrr|}
\hline miR-143-3p & 164.3 & 375.2 \\
\hline miR-145-5p & 7.5 & 15.2 \\
\hline
\end{tabular}

\begin{tabular}{|lrr|}
\hline miR-183-5p & 15.5 & 48.1 \\
\hline miR-182-5p & 960.7 & 1904.2 \\
\hline miR-96-5p & & \\
\hline
\end{tabular}

miR-96-5p

\begin{tabular}{lll}
\hline miR-497-5p & 9.7 & 27.8 \\
\hline miR-195-5p & &
\end{tabular}

\begin{tabular}{lll} 
miR-195-5p & 23.0 & 40.3 \\
\hline
\end{tabular}

\begin{tabular}{|lll|}
\hline miR-542-3p & 6.4 & 13.3 \\
\hline miR-450a-5p & 8.8 & 17.7 \\
\hline
\end{tabular}

\begin{tabular}{lll}
\hline miR-23a-3p & 665.8 & 1064.1 \\
\hline
\end{tabular}

$\begin{array}{lll}\text { miR-27a-3p } & 763.4 & 1145.7\end{array}$

\begin{tabular}{|lrr|}
\hline miR-493-5p & 35.9 & 59.5 \\
\hline miR-432-5p & 6.3 & 13.5 \\
\hline & & \\
\hline miR-362-5p & 15.2 & 23.2 \\
\hline miR-501-3p & 3.6 & 5.3 \\
\hline & & \\
\hline miR-181c-5p & 46.2 & 69.1 \\
\hline miR-181d-5p & 35.5 & 86.2 \\
\hline
\end{tabular}

\section{Down regulated Clusters}

\begin{tabular}{|lrr|}
\multicolumn{1}{|c}{} & \multicolumn{1}{c}{$\begin{array}{c}\text { Normoxia } \\
\text { TPM }\end{array}$} & \multicolumn{2}{c|}{ Hypoxia } \\
TPM
\end{tabular}

\section{Hypoxia:GBM correlation}

\begin{tabular}{|c|c|c|}
\hline MicroRNA & Hypoxia & GBM \\
\hline miR-155-5p & Up & Up \\
\hline miR-193a-3p & Up & Up \\
\hline miR-221-3p & Up & Up \\
\hline miR-221-5p & Up & Up \\
\hline miR-222-3p & Up & Up \\
\hline miR-324-5p & Up & Up \\
\hline miR-374a-5p & Up & Up \\
\hline miR-497-5p & Up & Up \\
\hline miR-628-5p & Up & Up \\
\hline miR-9-5p & Up & Up \\
\hline miR-99a-3p & Up & Up \\
\hline miR-182-5p & Up & Up \\
\hline miR-183-5p & Up & Up \\
\hline miR-210-3p & Up & Up \\
\hline miR-210-5p & Up & Up \\
\hline miR-23a-3p & Up & Up \\
\hline miR-30e-5p & Up & Up \\
\hline $\operatorname{miR}-335-3 p$ & Up & Up \\
\hline miR-335-5p & Up & Up \\
\hline miR-100-3p & Down & Down \\
\hline $\begin{array}{l}\text { miR-181a-2- } \\
3 p\end{array}$ & Down & Down \\
\hline miR-185-5p & Down & Down \\
\hline miR-29b-1-5p & Down & Down \\
\hline
\end{tabular}

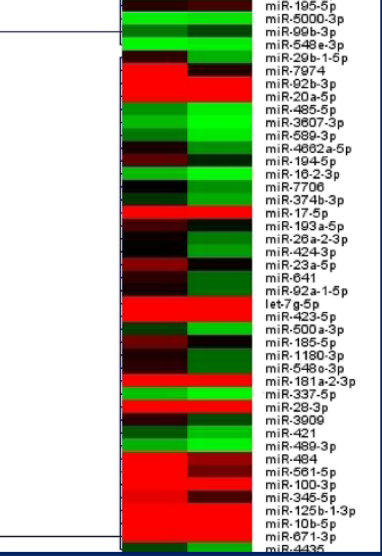

Figure 1 Hypoxia regulated miRNAs. Hierarchical clustering of hypoxia-induced and down-regulated miRNAs (>1.5-fold) in response to hypoxia $\left(0.2 \% \mathrm{O}_{2}\right)$ in cell line U87MG (a). List of hypoxia-regulated miRNA clusters in U87MG cells (b). A table showing correlation of microRNAs altered in hypoxia or in GBM tumor tissues (c) 


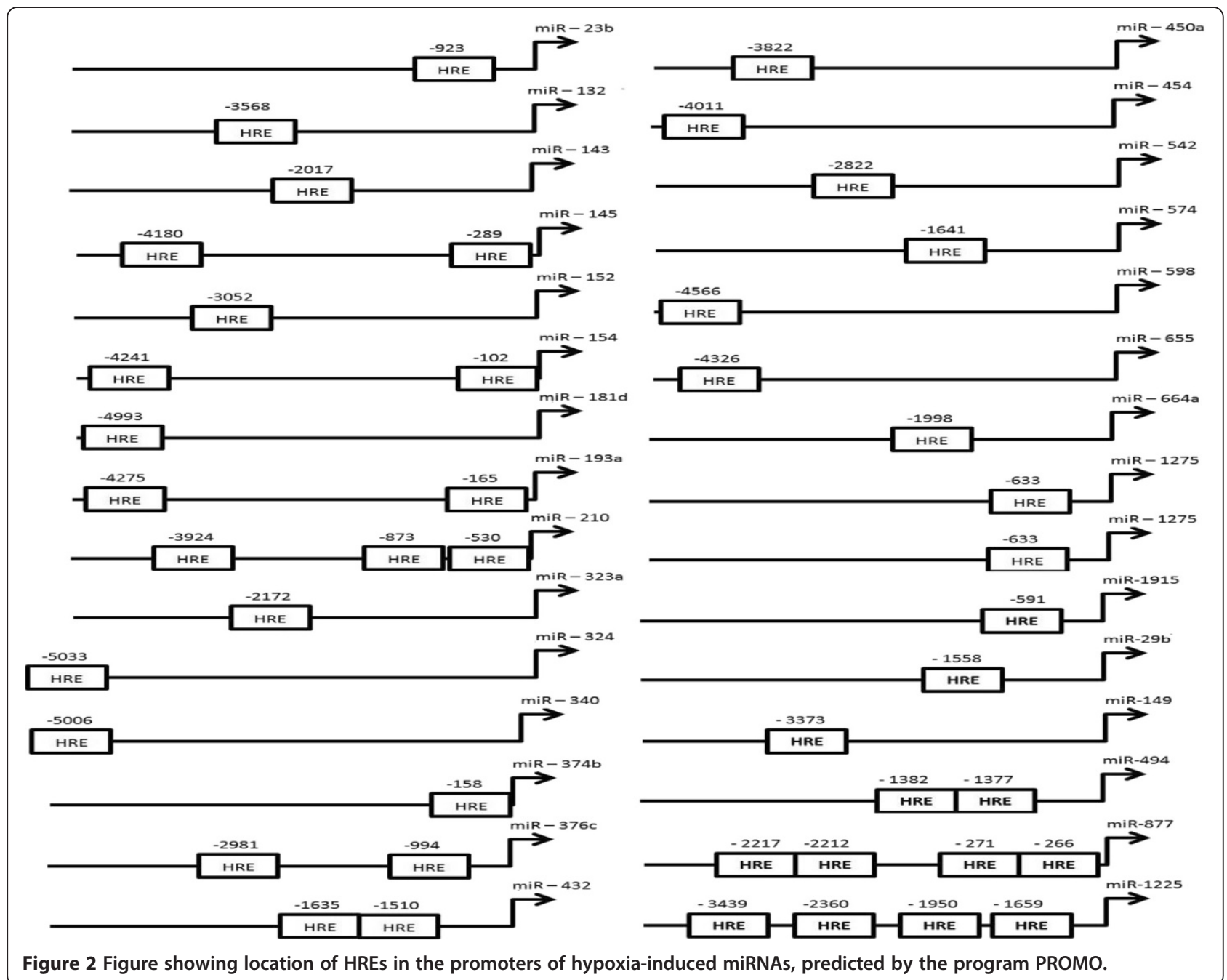

normoxia, we expressed a HIF1A mutant (proline to alanine mutations) that is extremely stable. Interestingly, miRNAs upregulated under hypoxia and containing HREs showed a higher expression in HIF1A transfected cells than in control cells. MiR-210-3p showed an about 5-fold and miR-1275, miR-376c-3p, miR-23b-3p, miR-193a-3p and miR-145-5p showed an about 2-fold induction in HIF1A transfected cells (Figure 3c). In parallel, we transfected U87MG cells with a control plasmid (pLK0.1-shGFP) or a shHIF1A over-expressing plasmid (pLK0.1-shHIF1A) and exposed the cells to hypoxia $\left(0.2 \% \mathrm{O}_{2}\right)$ for $48 \mathrm{~h}$. The transcript level of HIF1A was determined and was found to be down-regulated up to 2.4-fold compared to control cells in hypoxia (Figure $3 \mathrm{~d}$ ). As expected, downregulation of HIF1A by using specific shRNA inhibited hypoxia-mediated induction of these miRNAs (Figure 3e). Overall, these results show that expression of miR-210-3p, miR-1275, miR-376c-3p, miR-23b-3p, miR-193a-3p and miR-145-5p is HIF-1 dependent.
MiR-210-3p promotes HIF transcriptional activity

We also tested if a feedback loop of the miR-210-3p and HIF pathways exists. MiR-210-3p levels were modulated under hypoxia, and HIF transcriptional activity was measured using a control HRE luciferase vector. Interestingly, miR-210-3p overexpression led to an increase in HRE activity, while miR-210-3p inhibition led to a decrease (Figure 4a). This shows that miR-210-3p promotes HIF transcriptional activity, which was also reflected in the increase in expression of the HIF target genes VEGF and CA9 in response to miR-210-3p over-expression and in their down-regulation in response to miR-210-3p inhibition (Figure 4b, c).

\section{MiR-210-3p a putative novel hypoxia marker in GBM patients}

Hypoxia is a critical aspect of the glioma microenvironment, and it has been associated with poor prognosis [38]. Thus, the hypoxic state of GBM tumors is often measured to predict patient treatment response [39]. Also, identifying 


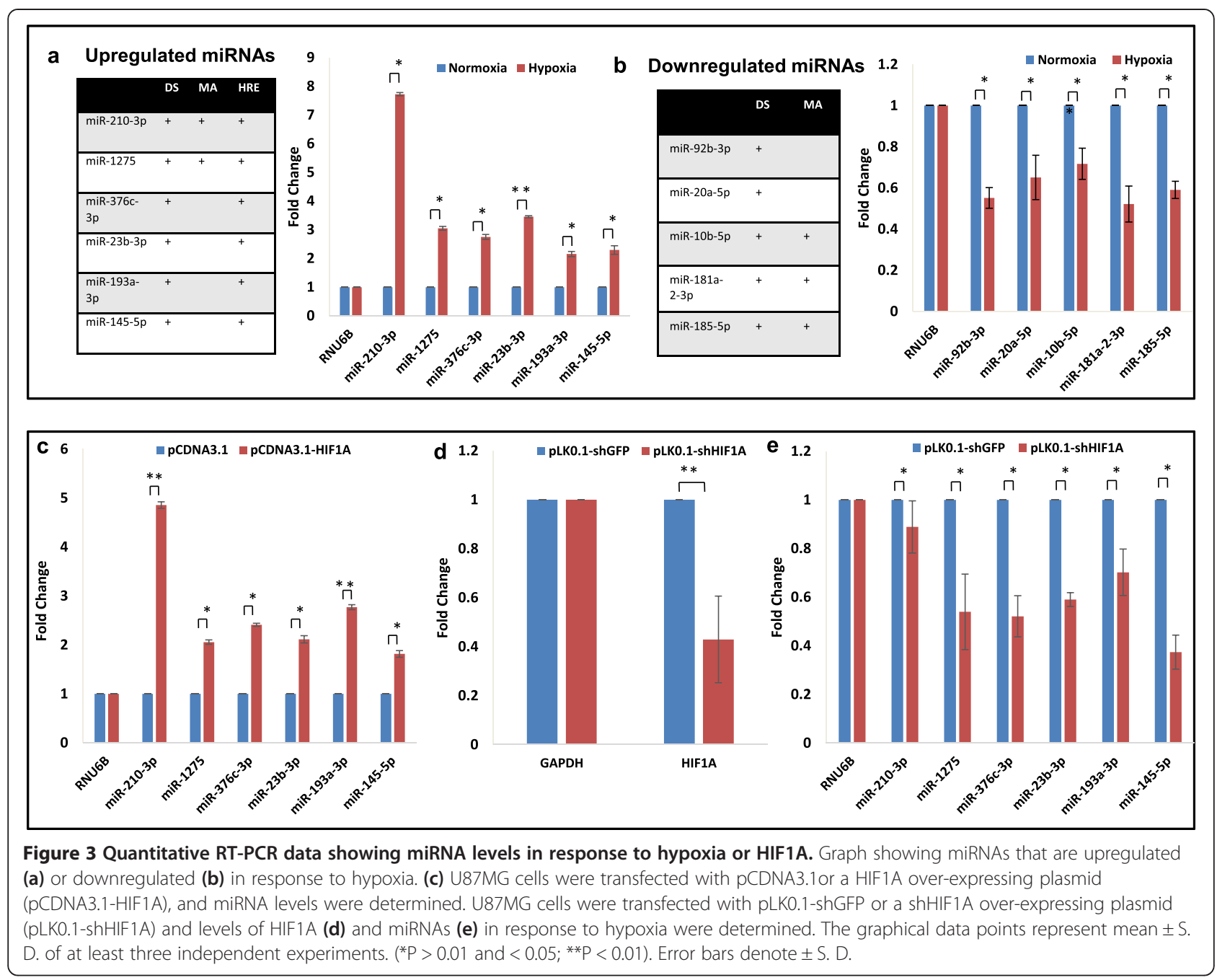

hypoxia-related molecular targets may be useful to develop novel treatment approaches.

Since miR-210-3p is highly up-regulated in hypoxic GBM cells, as identified by deep sequencing and other detection methods like microarray and quantitative stem loop RT-PCR, its level was assessed in 30 GBM patient samples, and efforts were made to correlate the levels with known hypoxia marker genes in GBM. Notably, miR-210-3p was highly expressed ( $>1.5$ fold, $\mathrm{p}<0.05$ in $30 / 30$; $>2.0$ fold, $\mathrm{p}<0.05$ in 22/30) GBM patient samples as compared to normal control (Figure 5a). Further, transcript levels of hypoxic markers VEGF and CA9 were also checked in patients, and normal samples and correlations were tested between miR-210-3p and VEGF/CA9 levels. We found that 27 out of $30 \mathrm{GBM}$ samples showed $\mathrm{a}>2$ fold increased VEGF/CA9 expression level compared to normal, suggesting their high hypoxic content (Figure 5b). Interestingly, miR-210-3p levels were found to be highly correlated (Pearson correlation coefficient $>0.8$ ), with both hypoxic markers, suggesting that miR-210-3p is regulated by hypoxia in GBM tumor tissues and may serve as an intrinsic hypoxia marker (Figure 5c, d).

\section{MiR-210-3p promotes hypoxia/stress/chemo-resistance in GBM}

Several hypoxia-regulated microRNAs have been reported to modulate survival, growth advantage and therapy resistance of cancer cells [40]. We thus investigated whether miR-210-3p plays a similar role. MiR-210-3p over-expression and silencing strategies were used to analyse its functions. Quantitative RT-PCR data show that miR-210-3p was $\sim 4.2$ fold up-regulated in miR-210-3p over-expressing U87MG cells (Additional file 11a), while miR-210-3p was down regulated up to $\sim 5.6$ fold in U87MG cells transiently transfected with a miR-210-3p inhibitor (Additional file 11b). Interestingly, miR-210-3p overexpressing U87MG, U251MG and A172 cells showed better survival in tumor microenvironment conditions, i.e. hypoxia and serum starvation, while the GBM cells 


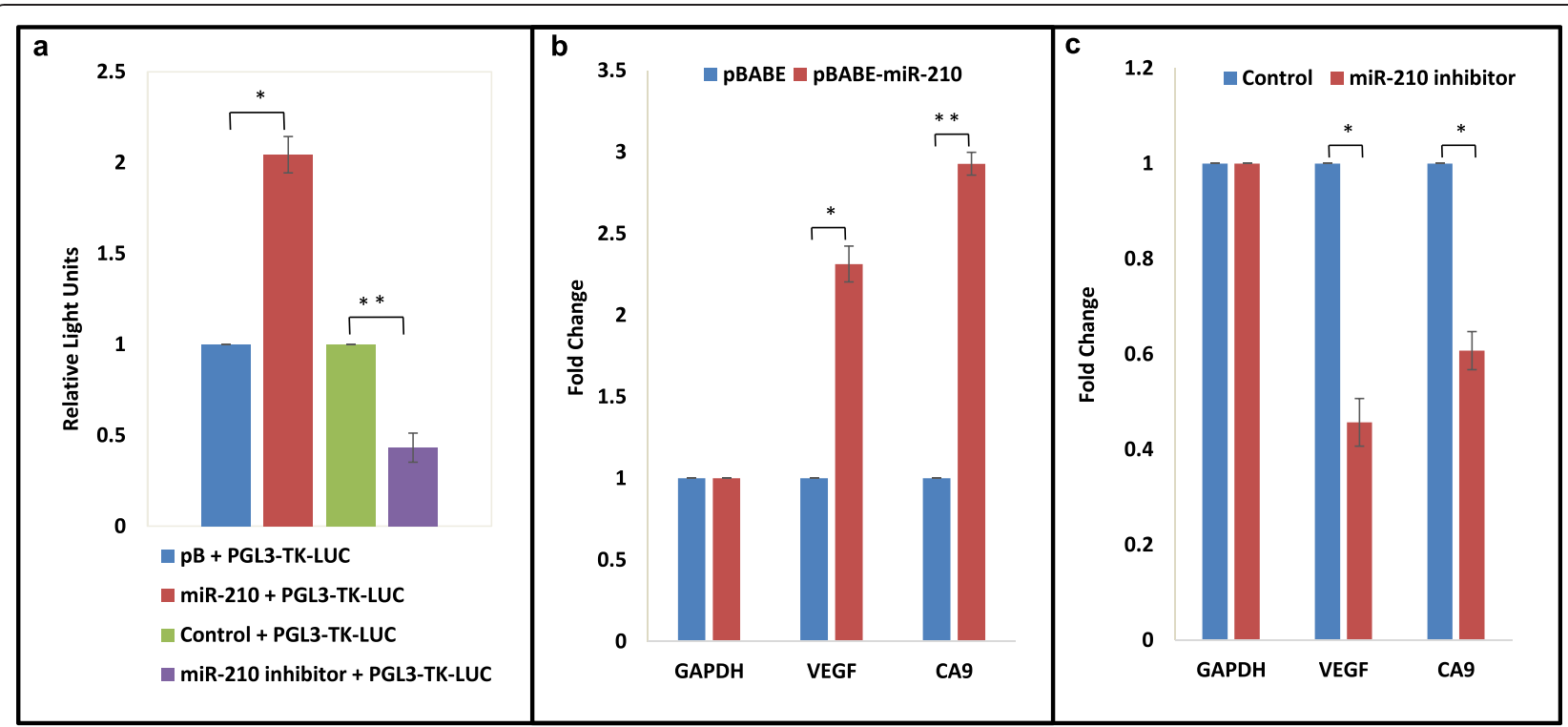

Figure 4 MiR-210-3p induces HIF transcriptional activity. U87MG cells were transfected with a HRE luciferase vector, along with either miR-210-3p overexpression - [(pBABE-miR210) or control (pBABE)] or inhibition - [(miR-210 inhibitor) or (control)] vectors, and HRE transcriptional activity was assayed (a). U87MG cells were transiently transfected with either a miR-210-3p over-expression vector (pBABE-miR-210) or the empty pBABE-puro parent vector (b) or with either a miR-210-3p inhibitor or control oligos (c), and VEGF/CA9 levels were determined by qRT-PCR. The graphical data points represent mean \pm S.D. of at least three independent experiments. ( ${ }^{*} P>0.01$ and $<0.05$; $\left.{ }^{* *} P<0.01\right)$. Error bars denote $\pm S$. D.

transfected with the miR-210-3p inhibitor showed the opposite trend (Figure 6a, b). Moreover, miR-210-3p over-expressing GBM cells showed increased resistance to temozolomide (a routinely used drug for GBM patients) mediated death while miR-210-3p inhibition made cells more sensitive (Figure 6c). Overall, miR-210-3p seems to promote aggressiveness and therapy resistance of GBM cells.

\section{MiR-210-3p targetome}

MicroRNAs exert their effect either by binding directly to the 3' UTRs of target transcripts, or indirectly by inhibiting the expression of transcription factors or regulators. We performed in silico searches, as described in the "Methods", to identify target transcripts of miR-210-3p (Additional file 7). Interestingly, HIF3A, a negative regulator of hypoxic response was identified as putative target of miR-210-3p by three target prediction programs (PITA, miRanda and RNAhybrid). To determine the effect of miR-210-3p on HIF3A transcript, we transiently overexpressed miR-210-3p in U87MG cells and determined the HIF3A transcript level $48 \mathrm{~h}$ post-transfection by qRT-PCR. We found $\sim 0.6$ fold downregulation at the transcript level (Figure 7a).

To further validate the results from qRT-PCR, a HIF3A 3'UTR-luciferase reporter assays were performed. Interestingly, results showed robust downregulation ( $\sim 0.2$ fold) in luciferase activity, suggesting that miR-210-3p binding to the HIF-3A 3'UTR leads to its downregulation. To verify this, the miR-210-3p binding site in the HIF3A 3'UTR was mutated through site-directed mutagenesis (Figure 7b). As anticipated, only minimal inhibition was observed when the mutated 3'UTR was used, suggesting HIF3A to be a direct target of miR-210-3p (Figure 7c).

\section{Discovery of novel miRNAs}

Deep sequencing profiling of sRNAs is a powerful tool for the identification of novel miRNAs, since this method is independent of the prior knowledge of candidate sequences. Since miRNAs mainly arise from intergenic and intronic regions of genomes, sequence reads that matched these regions were extracted along with 70 nucleotide flanking regions from both ends. Novel miRNAs were predicted using various miRNA identification algorithms, as described in the "Methods".

A total of 139 novel miRNAs were predicted, with only 14 common in both the samples. A total of 7 miRNAs also exhibited isomiRs that differed from the standard mature sequence by a few nucleotides, mostly at the 3' end (Additional file 4). A total of 7 miRNAs showed more than 10 reads. Secondary structures of these are shown, as predicted by RNAfold [41] (Figure 8a). Three of these novel miRNAs with higher read numbers were validated by quantitative stem loop RT-PCR and, in agreement with the deep sequencing reads, displayed differential expression (Figure $8 \mathrm{~b}$ ). The novel miRNAs, iithsa_40 and iithsa_92 showed an about 3-fold reduced level, while iithsa_15 showed induction of expression in hypoxic cells, as determined by real time PCR. We also 

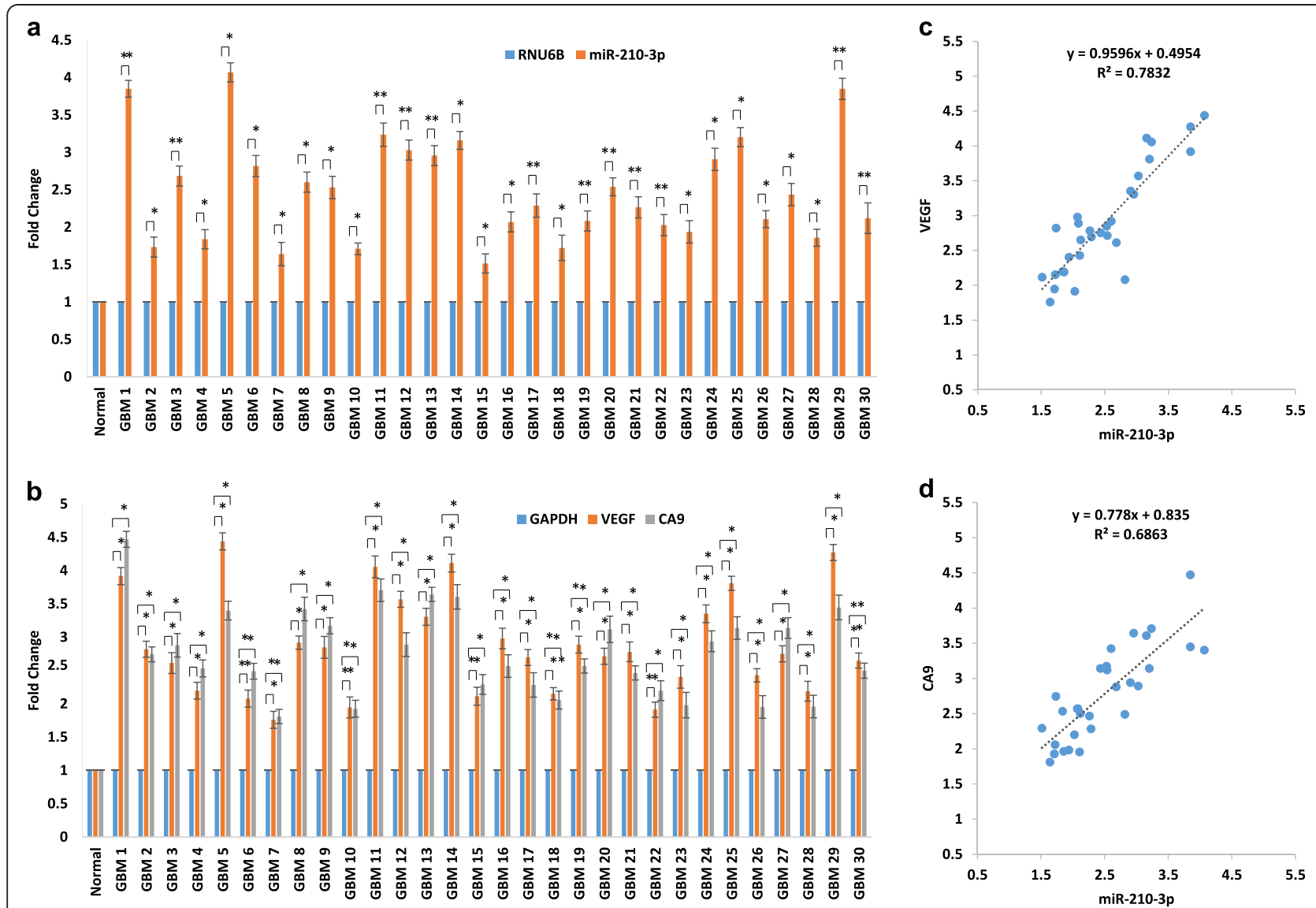

Figure 5 Quantitation and correlation of miR-210-3p levels with hypoxia markers VEGF and CA9. The graph showing levels of miR-210 (a) and VEGF, CA9 (b) in normal and GBM tumor tissue $(n=30)$ samples using qRT-PCR. Correlation between miR-210-3p and VEGF (c) and miR-210-3p and CA9 (d) in GBM tumor tissues. The miR-210-3p levels have been normalized with RNU6B, while GAPDH was used for VEGF and CA9 normalization. The graphical data points in $a$ and $b$ represent mean \pm S.D. of at least three independent experiments. $\left({ }^{*} P>0.01\right.$ and $\left.<0.05 ;{ }^{*} P<0.01\right)$. Error bars denote \pm S. D.

performed target site analyses of these three hypoxiaregulated novel miRNAs. The target lists were compared with the hypoxia-regulated mRNA list in GBM [42] (Additional file 7). Interestingly, we found that iithsa_40 showed inverse correlation with SERPINE1, while iithsa_15 showed inverse correlation with hypoxia-regulated genes HNRNPA1 and EIF2C1. What significance these correlations have, needs to be investigated. We could further validate by qRT-PCR the expression of 2 novel miRNAs having 1-3 reads, using a higher amount of template cDNA (Figure $8 \mathrm{~b}$ ). This was particularly important to distinguish the fact whether novel miRNAs displaying 1 reads were really existent or they appear as a result of sequencing error.

\section{Discussion}

This study sheds light on the sRNA composition of GBM cell line U87MG and its alteration in response to severe $\left(0.2 \% \mathrm{O}_{2}\right)$ and chronic $(48 \mathrm{~h})$ hypoxia, using deep sequencing of sRNA populations. The analysis of the deep sequencing reads reveals that miRNAs form the most abundant class of sRNA (75-80\%) in both normoxic and hypoxic samples. A total of 643 and 627 mature miRNAs were found to be expressed in normoxic and hypoxic cells, respectively, with a range of expression from 1 to $>10,000$ reads. Interestingly, miRNAs expressed within a cluster also showed a large variation in expression. This was also reported in recent papers, based on analysis of deep sequencing reads. The reason for this variation remains unclear. Possible explanations may be the use of different promoters, different post-transcriptional processing or differences in stability of mature miRNAs. We identified several highly expressed miRNAs $(>0.1$ million counts) in GBM cells. A comparison with published lists of highly expressed miRNAs from other cancer cell lines shows that the highly expressed miRNA pool varies between cell lines. Secondly, some of the highly expressed miRNAs in GBM cells are known oncomiRs (miR-21, let-7a and miR-92a). A total of 31 piRNAs were found to be expressed in GBM cells, with 7 of them 




being differentially expressed under hypoxia. It would be interesting to see whether piRNAs play any role in the hypoxic response.

Differentially expressed miRNAs identified using deep sequencing and/or microarray hybridization were further verified by stem-loop qRT-PCR on two GBM cell lines. Subsets of these miRNAs were found to bear HREs in their promoters, similar to hypoxia-regulated protein coding gene promoters. We validated expression and HIF1A dependent induction of miR-210-3p, miR-1275,
miR-376c-3p, miR-23b-3p, miR-193a-3p and miR-145-5p in U87MG using HIF1A over-expression and silencing experiments. Since recent studies highlighted specific miRNAs that may directly or indirectly control HIF1A levels and hypoxia-inducible gene expression, we cannot rule out the existence of a positive or negative feedback loop in relation to these HRMs. For example, miR210-3p represses glycerol-3-phosphate dehydrogenase 1-like (GPD1L) which, in turn, stabilizes HIF-1A by reducing hyper-hydroxylation [43]. Interestingly, our 

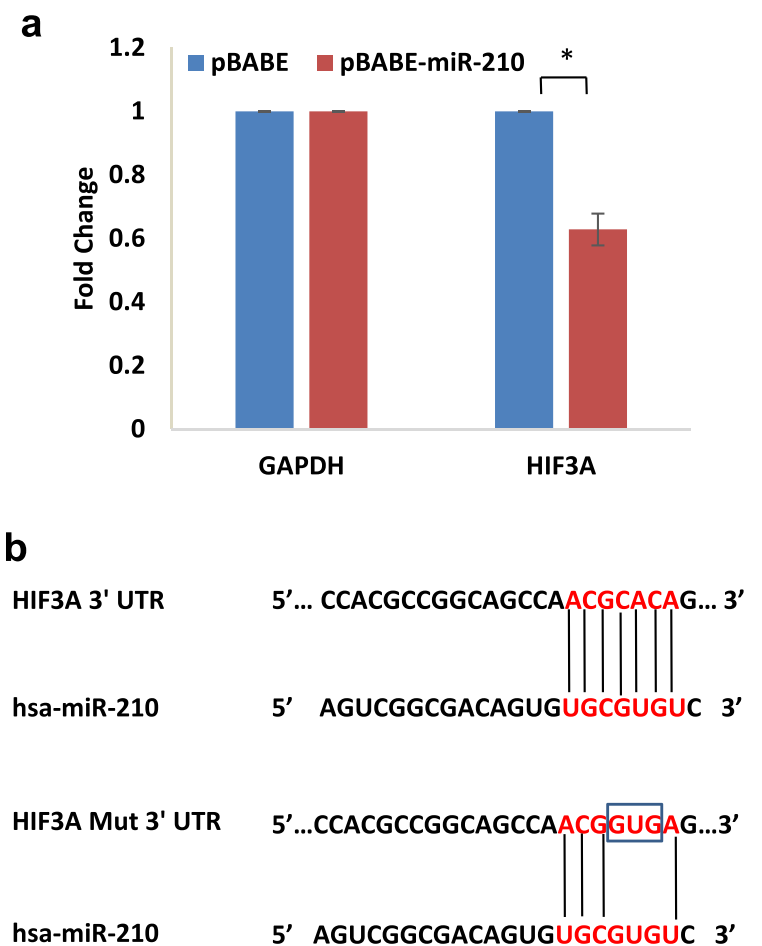

C

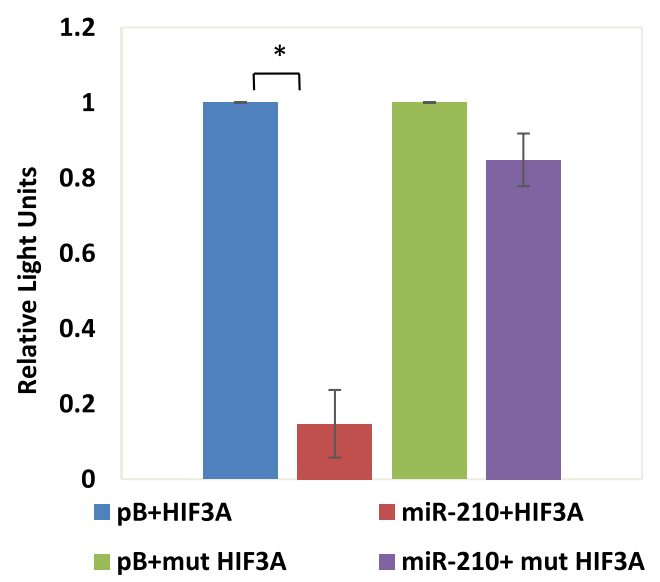

Figure 7 MiR-210-3p targets HIF3A. Effect of transient over-expression of miR-210-3p on HIF3A transcript levels was determined by qRT-PCR (a). Diagram showing wild type/mutated miR-210-3p binding site in the HIF3A 3' UTR (b). 3' UTR luciferase results obtained by cotransfection of luciferase constructs bearing wild type/mutated miR-210-3p binding sites in the HIF3A 3' UTR, along with miR-210-3p over-expression vector (pBABE-miR-210) or the empty pBABE-puro parent vector (c). The graphical data points in a and $c$ represent mean \pm S.D. of at least three independent experiments. ( ${ }^{*} \mathrm{P}>0.01$ and $<0.05$; ${ }^{*} \mathrm{P}<0.01$ ). Error bars denote \pm S. D.

results identify HIF3A (a negative regulator of hypoxic response) as direct target of miR-210-3p. It has been shown before that ectopic expression of HIF3A results in downregulation of VEGF and results in reduced vascular density of tumors and slower tumor growth in vivo [44]. Thus, it is possible that miR-210-3p, through downregulation of HIF3A, may be part of a novel mechanism of positive feedback regulation of angiogenesis and maintenance of a vascular phenotype in GBM. In addition, we see that miR210-3p over-expression also leads to induction of HIF transcriptional activity and then also of its targets VEGF and CA9. In contrast, miR-210-3p-inhibition under hypoxia prevents HIF mediated induction of VEGF and CA9. Overall, these results suggest that miR-210-3p is involved in induction of the HIF pathway.

In contrast, some miRs, such as the miR-17-92 cluster [45] and miR-519 [46] have been shown to down-regulate the HIF1A transcript. The possibility of regulation of HRMs by other transcription factors like TWIST, peroxisome proliferator-activated receptors $\gamma$ (PPAR $\gamma$ ), or GATA1, also exists [47-49]. Several HRMs like miR-210, -23b, -335 and -193a have been reported to be hypoxia-inducible in other cell lines too $[19,50,23]$. However, whether hypoxia-mediated regulation of miRNAs like miR$1275,-708,-129,-455$ is GBM-specific or occurs in other cell types too needs to be investigated.

Overall, miR-210 showed the highest induction ( 25-fold - deep sequencing, 3-fold - microarray, $\sim 8$ fold - qRT-PCR) in response to hypoxia. Interestingly, we also noticed a $>4$ fold induction of miR-210 isomiR species in the hypoxic sample (312), compared to the normoxic one (73). Several of these isomiRs also showed differential expression under hypoxia. The isomiR generation has been correlated to differential processing by miRNA processing enzymes Drosha and Dicer [51]. Whether, dicer processivity is altered under hypoxia in GBM remains to be seen. Another possibility is that certain nucleotide transferases become activated under hypoxia and add nucleotides to certain miRNAs. What effect these additions have on miRNA stability or target binding needs further investigation.

Though miR-210-3p has been well established as a HRM/hypoxamiR in several cancers, its role in the context of GBM remains unclear. Our findings indicate that miR-210-3p functions as an oncomiR in GBM. We show that high miR-210-3p-levels in GBM promote cell survival in the tumor microenvironment (under hypoxia and nutrient deprivation) and provide the cells with resistance to temozolomide mediated death. Whether survival as measured by the MTT assay involves miR-210-3p-mediated increased cell proliferation or decreased apoptosis remains to be seen. In other studies, miR-210 has been shown to modulate mitochondrial oxygen uptake and create a pseudo-hypoxic environment [52], or to act as an oncomiR by repressing the Myc antagonist Max-binding protein [53] (MNT) and as pro-angiomir by targeting ephrin-A3 [54] in other cancers. A recent publication also shows miR-210-3p as a hypoxia-regulated miRNA in a GBM cell line [55]; 


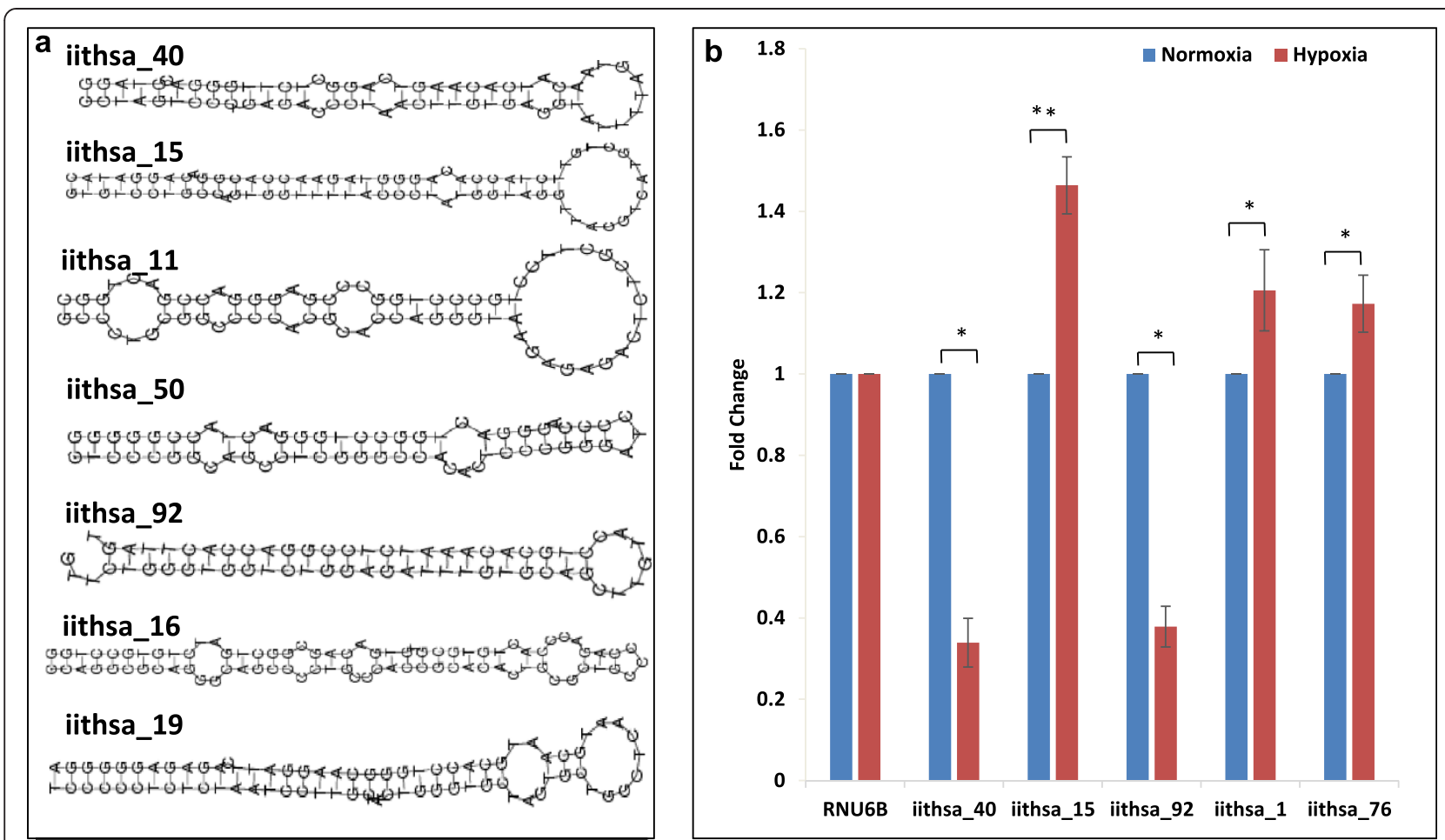

Figure 8 Identification of novel miRNAs. (a) Secondary structure prediction of highly expressed novel miRNAs using RNA-fold. (b) Detection of novel miRNAs through Real-time PCR in normoxic and hypoxic samples. The graphical data points in b represent mean \pm S.D. of at least three independent experiments. ${ }^{*} \mathrm{P}>0.01$ and $\left.<0.05 ;{ }^{* *} \mathrm{P}<0.01\right)$. Error bars denote $\pm S$. $\mathrm{D}$.

however, its function remains unexplored. Overall, which role these HRMs play in GBM pathogenesis has not been elucidated. Based on the current literature, some of them act as oncomiRs and promote drug resistance in GBM. MiR-23b is highly expressed in GBM tumors and its up regulation is correlated with tumor survival [56]. Similarly, overexpression of miR-335 is associated with poor prognosis in human glioma [57]. MiR-455 promotes acquired temozolomide resistance in GBM [58]. MiR-193a is associated with poor survival in GBM [59]. MiR-183 up-regulates HIF-1A by targeting isocitrate dehydrogenase 2 [60]. On the other hand, hypoxia-down-regulated miR-29b inhibits invasion and proliferation of GBM [61]. Overall, these observations are in line with the current understanding that hypoxia promotes GBM aggressiveness and these HRMs may play a prominent role in it.

We compared our hypoxia-regulated miRNA list with published lists of miRNAs that are known to be deregulated in GBM tumor tissues. Interestingly, we found that hypoxia-induced microRNAs such as miR-221, 222, miR-155, miR-210, etc., are also overexpressed in GBM tumor tissues, suggesting that hypoxia may be one of the major factors contributing to their elevated expression.

A particularly interesting finding of our study is a positive linear correlation of the level of miR-210-3p with that of hypoxic markers (VEGF, CA9) in GBM patient samples. This suggests that the level of miR-210-3p in GBM tumors depends on the in vivo $\mathrm{O}_{2}$ concentration in the tumor. Considering the more stable nature of miRNAs compared to the more labile mRNAs, miR-210-3p may show a better potential as intrinsic hypoxia marker for GBM tumor samples than VEGF and CA9 $(7,8)$. Also, target gene analyses of miR-210-3p in these tumor samples may hint at pathways responsible for hypoxia-resistance in GBM.

We discovered a total of 139 novel miRNAs in U87MG cells, using predictions of programs CID-miRNA and miPred. We validated the expression of five novel miRNAs and found three to be differentially expressed. The functional role of these novel miRNAs is not yet known. Importantly, the detection of two novel miRNAs, showing only 1-3 reads in either sample proves that these single reads are not mere sequencing errors, but rather very low abundant novel miRNAs. Specific novel miRNAs, also showed the presence of isomiRs. The isomiRs carried mostly extra nucleotides at their 3 'ends, suggesting generation as a result of inappropriate DICER processing.

\section{Conclusions}

This study is a first effort to identify hypoxic signatures of miRNA in GBM, using deep sequencing and microarray technologies. We identify miR-210-3p as a HIF regulated 
miRNA that acts as critical mediator of the hypoxic response and thus as an oncomiR in GBM. The regulatory and functional characterization of other identified known and novel HRMs may help with the identification of novel hypoxia biomarkers and therapeutic targets for GBM.

\section{Consent}

Written informed consent was obtained from the patient for the publication of this report and any accompanying images.

\section{Additional files}

Additional file 1: A detailed analyses of the sRNA deep sequencing data. Read lengths, annotations, expression patterns, miRNA cluster analyses and a list of highly expressed miRNAs and piRNAs are given.

Additional file 2: The known miRNA expression pattern in response to normoxia (Sheet 1) and hypoxia (Sheet 2).

Additional file 3: List of up-regulated (Sheet 1) and down-regulated (Sheet 2) miRNAs showing > 1.5-fold difference in response to hypoxia in U87MG cells, as determined by deep sequencing. The data were normalised using TPM or RPKM for each sample.

Additional file 4: List of the predicted novel miRNAs with their isomiR sequences.

Additional file 5: List of up-regulated (Sheet 1) and down-regulated (Sheet 2) miRNAs showing $>0.6$ fold (log base 2 ) difference in response to hypoxia in U87MG cells, as determined by microarray profiling.

Additional file 6: List of primers used for detection of specific miRNAs and mRNAs with Quantitative RT-PCR and for cloning wild type/mutated 3' UTR of HIF3A.

Additional file 7: List of the predicted targets of miR-210-3p and differentially regulated novel miRs. The prediction was done using the program miRECORDS.

Additional file 8: List of HREs predicted in the promoter of miRNAs up-regulated in response to hypoxia, determined by deep sequencing and microarray profiling. The prediction was done using the program $\mathrm{PROMO}$

Additional file 9: Quantitative RT-PCR data showing miRNA levels in response to hypoxia. Graph showing miRNAs upregulated (a) or downregulated (b) in response to hypoxia in U251MG cells. The graphical data points represent mean \pm S.D. of at least three independent experiments. $\left({ }^{*} \mathrm{P}>0.01\right.$ and $\left.<0.05 ;{ }^{* *} \mathrm{P}<0.01\right)$. Error bars denote $\pm S$. D

Additional file 10: List of predicted isomiRs of miR-210-3p in normoxic and hypoxic U87MG cells, as determined by deep sequencing.

Additional file 11: Quantitative RT-PCR data showing the miR-210$3 p$ level in a miR-210-3p overexpressing U87MG cell line or control U87MG cells (a) and U87MG cells transiently transfected with miR210-3p inhibitor or control oligos (b), respectively. The graphical data points represent mean \pm S.D. of at least three independent experiments. $\left({ }^{*} P>0.01\right.$ and $\left.<0.05 ;{ }^{*} P<0.01\right)$. Error bars denote $\pm S$. D.

\section{Abbreviations}

HIF1A: Hypoxia inducible factor 1 A; CA9: Carbonic anhydrase 9; VEGF: Vascular endothelial growth factor; piRNA: Piwi interacting RNA; TPM: Transcripts parts per million; RPKM: reads per kilobase per million; GAPDH: Glyceraldehyde 3-phosphate dehydrogenase; lincRNA: Long intergenic non-coding RNA; snRNA: Small nuclear RNA; snoRNA: Small nucleolar RNA; scRNA: Small cytoplasmic RNA; HRM: Hypoxia regulated miRNA; HREs: HIF1A response elements.

\section{Competing interests}

The authors declare no competing financial or other interest in relation to this work.

\section{Authors' contributions}

RK and CS conceived the project. RK supervised the whole study. RA and PP performed analyses of deep sequencing data. RA performed all the wet experiments. PJ provided the RNA samples of GBM patients. VD performed the microarray experiment. RA and RK wrote the manuscript. All the authors read and approved the final manuscript.

\section{Acknowledgements}

RA thanks the Department of Biotechnology for a Senior Research Fellowship. This work was supported by the Department of Biotechnology, Government of India (BT/PR14295/MED/30/463/2010). The authors thank Prof. A. Bhattacharya from Jawaharlal Nehru University for useful discussion and support from his grant from Department of Biotechnology, Government of India. We would like to acknowledge Dr. Stefan Oehler for carefully editing this manuscript.

\section{Author details}

${ }^{1}$ Department of Biochemical Engineering and Biotechnology, Indian Institute of Technology, 110016 New Delhi, India. ${ }^{2}$ School of Computational and Integrative sciences, Jawaharlal Nehru University, 110067 New Delhi, India. ${ }^{3}$ Department of Pathology, All India Institute of Medical Sciences, 110029 New Delhi, India.

Received: 28 March 2014 Accepted: 12 August 2014

Published: 17 August 2014

\section{References}

1. Brown JM, Wilson WR: Exploiting tumour hypoxia in cancer treatment. Nat Rev Cancer 2004, 4:437-447

2. Melillo G: Inhibiting hypoxia-inducible factor 1 for cancer therapy. Mol Cancer Res 2006, 4:601-605.

3. Louis DN: Molecular pathology of malignant gliomas. Annu Rev Pathol 2006, 1:97-117.

4. Rich JN, Bigner DD: Development of novel targeted therapies in the treatment of malignant glioma. Nat Rev Drug Discov 2004, 3:430-446.

5. Brat DJ, Mapstone TB: Malignant glioma physiology: cellular response to hypoxia and its role in tumor progression. Ann Intern Med 2003, 138:659-668.

6. Jensen RL: Brain tumor hypoxia: tumorigenesis, angiogenesis, imaging, pseudoprogression, and as a therapeutic target. J Neurooncol 2009, 92:317-335.

7. Said HM, Polat B, Staab A, Hagemann C, Stein S, Flentje M, Theobald M, Katzer A, Vordermark D: Rapid detection of the hypoxia-regulated CA-IX and NDRG1 gene expression in different glioblastoma cells in vitro. Oncol Rep 2008, 20:413-419.

8. Said HM, Hagemann C, Staab A, Stojic J, Kühnel S, Vince GH, Flentje M, Roosen K, Vordermark D: Expression patterns of the hypoxia-related genes osteopontin, CA9, erythropoietin, VEGF and HIF-1a in human glioma in vitro and in vivo. Radiother Oncol 2007, 83:398-405.

9. Seidel S, Garvalov BK, Wirta V, von Stechow L, Schänzer A, Meletis K, Wolter M, Sommerlad D, Henze A-T, Nistér M, Reifenberger G, Lundeberg J, Frisén J, Acker T: A hypoxic niche regulates glioblastoma stem cells through hypoxia inducible factor 2 alpha. Brain 2010, 133:983-995.

10. Calin GA, Croce CM: MicroRNA signatures in human cancers. Nat Rev Cancer 2006, 6:857-866.

11. Croce CM: Oncogenes and cancer. N Engl J Med 2008, 358:502-511.

12. Lawler S, Chiocca EA: Emerging functions of microRNAs in glioblastoma. J Neurooncol 2009, 92:297-306.

13. Ciafrè SA, Galardi S, Mangiola A, Ferracin M, Liu CG, Sabatino G, Negrini M, Maira G, Croce CM, Farace MG: Extensive modulation of a set of microRNAs in primary glioblastoma. Biochem Biophys Res Commun 2005, 334:1351-1358.

14. Krichevsky AM, Gabriely G: miR-21: a small multi-faceted RNA. J Cell Mol Med 2009, 13:39-53.

15. Gillies JK, Lorimer IAJ: Regulation of p27Kip1 by miRNA 221/222 in glioblastoma. Cell Cycle 2007, 6:2005-2009. 
16. Xia H, Qi Y, Ng SS, Chen X, Li D, Chen S, Ge R, Jiang S, Li G, Chen Y, He ML, Kung HF, Lai L, Lin MC: microRNA-146b inhibits glioma cell migration and invasion by targeting MMPs. Brain Res 2009, 1269:158-165.

17. Sasayama T, Nishihara M, Kondoh T, Hosoda K, Kohmura E: MicroRNA-10b is overexpressed in malignant glioma and associated with tumor invasive factors, uPAR and RhoC. Int J Cancer 2009, 125:1407-1413.

18. Moore LM, Kivinen V, Liu Y, Annala M, Cogdell D, Liu X, Liu C-G, Sawaya R, Yli-Harja O, Shmulevich I, Fuller GN, Zhang W, Nykter M: Transcriptome and small RNA deep sequencing reveals deregulation of miRNA biogenesis in human glioma. J Pathol 2013, 229:449-459.

19. Kulshreshtha R, Ferracin M, Wojcik SE, Garzon R, Alder H, Agosto-Perez FJ, Davuluri R, Liu C-G, Croce CM, Negrini M, Calin GA, Ivan M: A microRNA signature of hypoxia. Mol Cell Biol 2007, 27:1859-1867.

20. $\mathrm{Hu} H$, Gatti RA: MicroRNAs: New players in the DNA damage response. $\mathrm{J} \mathrm{Mol}$ Cell Biol 2011, 3:151-158.

21. Ivan M, Harris AL, Martelli F, Kulshreshtha R: Hypoxia response and microRNAs: no longer two separate worlds. J Cell Mol Med 2008, 12:1426-1431

22. Fasanaro P, Greco S, Lorenzi M, Pescatori M, Brioschi M, Kulshreshtha R, Banfi C, Stubbs A, Calin GA, Ivan M, Capogrossi MC, Martelli F: An integrated approach for experimental target identification of hypoxiainduced miR-210. J Biol Chem 2009, 284:35134-35143.

23. Shen G, Li X, Jia Y, Piazza GA, Xi Y: Hypoxia-regulated microRNAs in human cancer. Acta Pharmacol Sin 2013, 34:336-341.

24. Hara S, Hamada J, Kobayashi C, Kondo Y, Imura N: Expression and characterization of hypoxia-inducible factor (HIF)-3alpha in human kidney: suppression of HIF-mediated gene expression by HIF-3alpha. Biochem Biophys Res Commun 2001, 287:808-813.

25. Mittelbronn M: The current WHO classification of tumours of the central nervous system: histopathology and additional diagnostic methods. Curr Med Imaging Rev 2010, 6:200-219.

26. Crosby ME, Kulshreshtha R, Ivan M, Glazer PM: MicroRNA regulation of DNA repair gene expression in hypoxic stress. Cancer Res 2009, 69:1221-1229.

27. Vaz C, Ahmad HM, Sharma P, Gupta R, Kumar L, Kulshreshtha R, Bhattacharya A: Analysis of microRNA transcriptome by deep sequencing of small RNA libraries of peripheral blood. BMC Genomics 2010, 11:288.

28. Tyagi S, Vaz C, Gupta V, Bhatia R, Maheshwari S, Srinivasan A, Bhattacharya A: CID-miRNA: a web server for prediction of novel miRNA precursors in human genome. Biochem Biophys Res Commun 2008, 372:831-834.

29. Jiang $P$, Wu H, Wang W, Ma W, Sun X, Lu Z: MiPred: classification of real and pseudo microRNA precursors using random forest prediction model with combined features. Nucleic Acids Res 2007, 35:W339-W344.

30. Xiao F, Zuo Z, Cai G, Kang S, Gao X, Li T: MiRecords: an integrated resource for microRNA-target interactions. Nucleic Acids Res 2009, 37:D105-D110.

31. Messeguer $X$, Escudero R, Farré $D$, Núñez O, Martínez J, Albà MM: PROMO: detection of known transcription regulatory elements using species-tailored searches. Bioinformatics 2002, 18:333-334.

32. Farré $\mathrm{D}$, Roset $\mathrm{R}$, Huerta $M$, Adsuara JE, Roselló $\mathrm{L}$, Albà MM, Messeguer $\mathrm{X}$ : Identification of patterns in biological sequences at the ALGGEN server: PROMO and MALGEN. Nucleic Acids Res 2003, 31:3651-3653.

33. Henriksen M, Johnsen KB, Andersen HH, Pilgaard L, Duroux M: MicroRNA expression signatures determine prognosis and survival in glioblastoma multiforme-a systematic overview. Mol Neurobiol 2014, 10:420-435.

34. Moller HG, Rasmussen AP, Andersen HH, Johnsen KB, Henriksen M, Duroux M: A systematic review of MicroRNA in glioblastoma multiforme: micro-modulators in the mesenchymal mode of migration and invasion. Mo/ Neurobiol 2013, 47:131-144.

35. Wang GL, Jiang BH, Rue EA, Semenza GL: Hypoxia-inducible factor 1 is a basic-helix-loop-helix-PAS heterodimer regulated by cellular $\mathrm{O} 2$ tension. Proc Natl Acad Sci U S A 1995, 92:5510-5514.

36. Bruning U, Cerone L, Neufeld Z, Fitzpatrick SF, Cheong A, Scholz CC, Simpson DA, Leonard MO, Tambuwala MM, Cummins EP, Taylor CT: MicroRNA-155 promotes resolution of hypoxia-inducible factor 1 \{alpha\} activity during prolonged hypoxia. Mol Cell Biol 2011, 31:4087-4096.

37. Huang X, Le Q-T, Giaccia AJ: MiR-210-micromanager of the hypoxia pathway. Trends Mol Med 2010, 16:230-237.

38. Evans SM, Judy KD, Dunphy I, Jenkins WT, Hwang W-T, Nelson PT, Lustig RA, Jenkins K, Magarelli DP, Hahn SM, Collins RA, Grady MS, Koch CJ: Hypoxia is important in the biology and aggression of human glial brain tumors. Clin Cancer Res 2004, 10:8177-8184.
39. Murat A, Migliavacca E, Hussain SF, Heimberger AB, Desbaillets I, Hamou MF, Rüegg C, Stupp R, Delorenzi M, Hegi ME: Modulation of angiogenic and inflammatory response in glioblastoma by hypoxia. PLoS One 2009, 4:e5947.

40. Cheng Q, Yi B, Wang A, Jiang X: Exploring and exploiting the fundamental role of microRNAs in tumor pathogenesis. Onco Targets Ther 2013, 6:1675-1684.

41. Gruber AR, Lorenz R, Bernhart SH, Neuböck R, Hofacker IL: The Vienna RNA websuite. Nucleic Acids Res 2008, 36:W70-W74

42. Kucharzewska P, Christianson HC, Welch JE, Svensson K, Fredlund E, Ringnér M, Mörgelin M, Bourseau-Guilmain E, Bengzon J, Belting M: Exosomes reflect the hypoxic status of glioma cells and mediate hypoxia-dependent activation of vascular cells during tumor development. Proc Natl Acad Sci U S A 2013, 110:7312-7317.

43. Kelly TJ, Souza AL, Clish CB, Puigserver P: A hypoxia-induced positive feedback loop promotes hypoxia-inducible factor 1alpha stability through miR-210 suppression of glycerol-3-phosphate dehydrogenase 1-like. Mol Cell Biol 2011, 31:2696-2706.

44. Makino Y, Cao R, Svensson K, Bertilsson G, Asman M, Tanaka H, Cao Y, Berkenstam A, Poellinger $\mathrm{L}$ : Inhibitory PAS domain protein is a negative regulator of hypoxia-inducible gene expression. Nature 2001, 414:550-554.

45. Taguchi A, Yanagisawa K, Tanaka M, Cao K, Matsuyama Y, Goto H, Takahashi T: Identification of hypoxia-inducible factor- 1 alpha as a novel target for miR-17-92 microRNA cluster. Cancer Res 2008, 68:5540-5545.

46. Cha S-T, Chen P-S, Johansson G, Chu C-Y, Wang M-Y, Jeng Y-M, Yu S-L, Chen J-S, Chang K-J, Jee S-H, Tan C-T, Lin M-T, Kuo M-L: MicroRNA-519C suppresses hypoxia-inducible factor-1alpha expression and tumor angiogenesis. Cancer Res 2010, 70:2675-2685.

47. Yang M-H, Wu M-Z, Chiou S-H, Chen P-M, Chang S-Y, Liu C-J, Teng S-C, Wu K-J: Direct regulation of TWIST by HIF-1alpha promotes metastasis. Nat Cell Biol 2008, 10:295-305.

48. Krishnan J, Suter M, Windak R, Krebs T, Felley A, Montessuit C, Tokarska-Schlattner M, Aasum E, Bogdanova A, Perriard E, Perriard JC, Larsen T, Pedrazzini T, Krek W: Activation of a HIF1a-PPARy Axis Underlies the Integration of Glycolytic and Lipid Anabolic Pathways in Pathologic Cardiac Hypertrophy. Cell Metab 2009, 9:512-524

49. Zhang F-L, Shen G-M, Liu X-L, Wang F, Zhao Y-Z, Zhang J-W: Hypoxia-inducible factor 1-mediated human GATA1 induction promotes erythroid differentiation under hypoxic conditions. J Cell Mol Med 2012, 16:1889-1899.

50. Pulkkinen K, Malm T, Turunen M, Koistinaho J, Ylä-Herttuala S: Hypoxia induces microRNA miR-210 in vitro and in vivo. Ephrin-A3 and neuronal pentraxin 1 are potentially regulated by miR-210. FEBS Lett 2008, 582:2397-2401.

51. Cloonan N, Wani S, Xu Q, Gu J, Lea K, Heater S, Barbacioru C, Steptoe AL, Martin HC, Nourbakhsh E, Krishnan K, Gardiner B, Wang X, Nones K, Steen JA, Matigian NA, Wood DL, Kassahn KS, Waddell N, Shepherd J, Lee C, Ichikawa J, McKernan K, Bramlett K, Kuersten S, Grimmond SM: MicroRNAs and their isomiRs function cooperatively to target common biological pathways. Genome Biol 2011, 12:R126.

52. Chan SY, Zhang YY, Hemann C, Mahoney CE, Zweier JL, Loscalzo J: MicroRNA-210 controls mitochondrial metabolism during hypoxia by repressing the Iron-Sulfur Cluster Assembly Proteins ISCU1/2. Cell Metab 2009, 10:273-284.

53. Zhang Z, Sun H, Dai H, Walsh RM, Imakura M, Schelter J, Burchard J, Dai X, Chang AN, Diaz RL, Marszalek JR, Bartz SR, Carleton M, Cleary MA, Linsley PS, Grandori C: MicroRNA miR-210 modulates cellular response to hypoxia through the MYC antagonist MNT. Cell Cycle 2009, 8:2756-2768.

54. Fasanaro P, D'Alessandra Y, Di Stefano V, Melchionna R, Romani S, Pompilio G, Capogrossi MC, Martelli F: MicroRNA-210 modulates endothelial cell response to hypoxia and inhibits the receptor tyrosine kinase ligand Ephrin-A3. J Biol Chem 2008, 283:15878-15883.

55. Lages E, Guttin A, El Atifi M, Ramus C, Ipas H, Dupré I, Rolland D, Salon C, Godfraind C, de Fraipont F, Dhobb M, Pelletier L, Wion D, Gay E, Berger F, Issartel JP: MicroRNA and target protein patterns reveal physiopathological features of glioma subtypes. PLoS One 2011, 6:e20600.

56. Chen L, Han L, Zhang K, Shi Z, Zhang J, Zhang A, Wang Y, Song Y, Li Y, Jiang T, Pu P, Jiang C, Kang C: VHL regulates the effects of miR-23b on glioma survival and invasion via suppression of HIF-1a/VEGF and $\beta$-catenin/Tcf-4 signaling. Neuro Oncol 2012, 14:1026-1036.

57. Jiang J, Sun X, Wang W, Jin X, Bo X, Li Z, Bian A, Jiu J, Wang X, Liu D, Hui X, Wang $Y$, Wang A, Ding L: Tumor microRNA-335 expression is associated with poor prognosis in human glioma. Med Oncol 2012, 29:3472-3477. 
58. Ujifuku K, Mitsutake N, Takakura S, Matsuse M, Saenko V, Suzuki K, Hayashi K, Matsuo T, Kamada K, Nagata I, Yamashita S: miR-195, miR-455-3p and miR-10a( $\left.{ }^{*}\right)$ are implicated in acquired temozolomide resistance in glioblastoma multiforme cells. Cancer Lett 2010, 296:241-248.

59. Srinivasan S, Patric IRP, Somasundaram K: A Ten-microRNA expression signature predicts survival in Glioblastoma. PLoS One 2011, 6:e17438

60. Tanaka H, Sasayama T, Tanaka K, Nakamizo S, Nishihara M, Mizukawa K, Kohta M, Koyama J, Miyake S, Taniguchi M, Hosoda K, Kohmura E: MicroRNA-183 upregulates HIF-1a by targeting isocitrate dehydrogenase 2 (IDH2) in glioma cells. J Neurooncol 2013, 111:273-283.

61. Cortez MA, Nicoloso MS, Shimizu M, Rossi S, Gopisetty G, Molina JR, Carlotti C, Tirapelli D, Neder L, Brassesco MS, Scrideli CA, Tone LG, Georgescu M-M, Zhang W, Puduvalli V, Calin GA: miR-29b and miR-125a regulate podoplanin and suppress invasion in glioblastoma. Genes Chromosomes Cancer 2010, 49:981-990.

doi:10.1186/1471-2164-15-686

Cite this article as: Agrawal et al: Hypoxic signature of microRNAs in glioblastoma: insights from small RNA deep sequencing. BMC Genomics 2014 15:686.

\section{Submit your next manuscript to BioMed Central and take full advantage of:}

- Convenient online submission

- Thorough peer review

- No space constraints or color figure charges

- Immediate publication on acceptance

- Inclusion in PubMed, CAS, Scopus and Google Scholar

- Research which is freely available for redistribution 